Human Ethology Bulletin - Proc. of the V. ISHE Summer Institute (2016): 1-3

Letter from the Editorial Board

\title{
ISHE MEETS IN AN ANTIQUE WORLD: A BRIEF REPORT ON THE V ISHE SUMMER INSTITUTE IN ATHENS, GREECE
}

\section{Susanne F. Schmehl}

Department of Anthropology, University of Vienna, Austria. susanne.schmehl@gmail.com

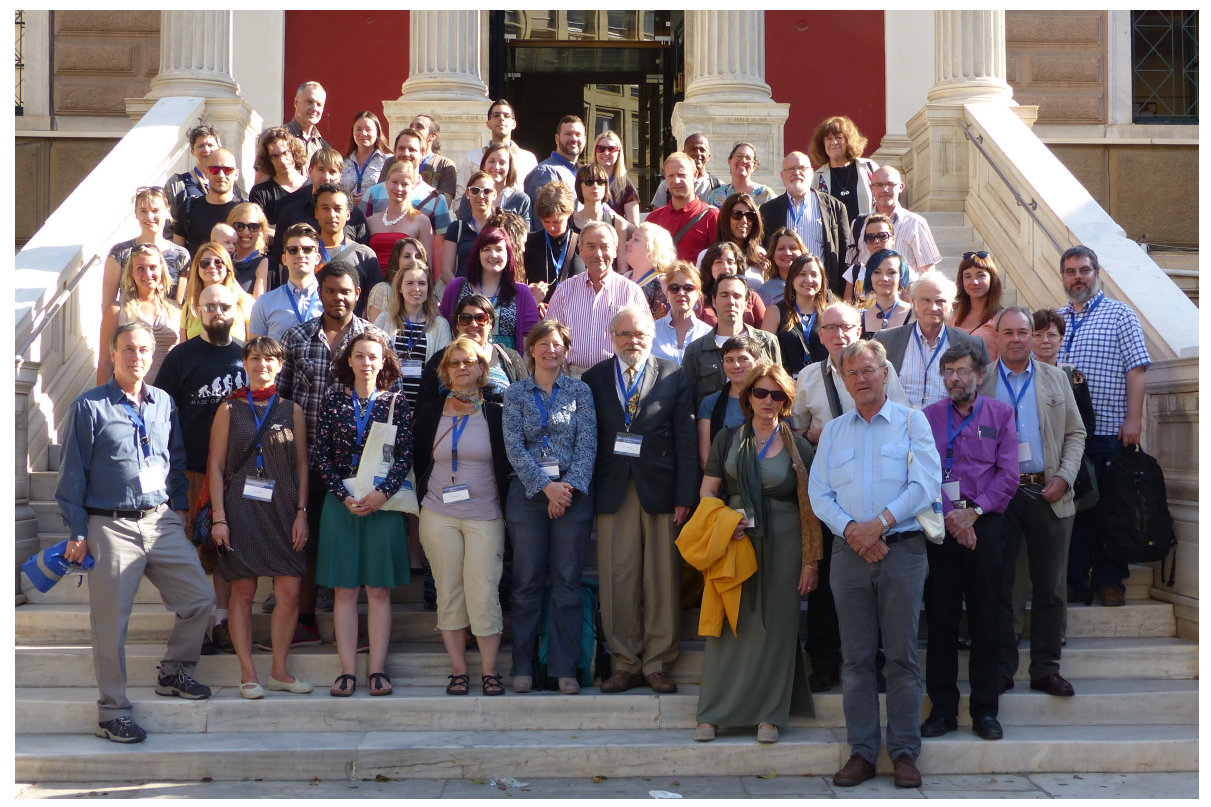

The Hellenic Human Ethology Group located in the city of Athens in Greece in cooperation with the National Technical University of Athens were the fantastic hosts of the V Biennal Summer Institute of the International Society for Human Ethology from the $13^{\text {th }}$ to the $16^{\text {th }}$ of May 2015. Hosting and organizing an ISHE meeting in Greece for the first time was of great significance for the Hellenic Human Ethology Group to strengthen this discipline in the country.

On the one hand ISHE Summer Institutes intend to offer students an opportunity to present their current research, exchange acquired knowledge and learn from experienced researchers, on the other hand experienced researchers have an unique chance to broaden their horizon by coming across new or hitherto unfamiliar approaches. Continuing this 
tradition, the ISHE crowd enjoyed three and a half days full of interesting talks, posters and workshops that fostered cooperation as well as fruitful and productive exchange of experiences and research initiatives.

The plenary talk by Christopher Henshilwood and Karen van Niekerk on behavioral evolution in southern Africa on the one hand and the historical survey on the human condition from classic Greek thinkers to present day human ethology given by Wulf Schiefenhövel on the other reflected on the importance of a holistic approach and interdisciplinarity when it comes to the investigation respectively interpretation of our human nature. The latter talk took place in the impressive halls of the neoclassical old parliament building of Athens and convinced not only with its historical content, but also the atmosphere was incredibly immersive and fascinating.

Another wonderful plenary talk by Peter K. Smith scrutinized the history of play and the evidence of developmental functions especially as regards to humans but also animals. The topic of play was further addressed by Glenn Weisfeld and Carol Cronin Weisfeld in their talk about the legacy and work of Owen Aldis. A paper reviewing the role of play as an emotion can be found as a theoretical review in this issue (Weisfeld \& Cronin Weisfeld, 2016).

Further oral presentations and posters covered a broad variety of novel investigations and research ideas ranging from sex differences in caffeine and calorie consumption (Sloan Kruger, Castor \& Kruger, 2016) to the recognition of disgust and facial expressions across the menstrual cycle (Mikolić, 2016). In the symposium on ethology and art the ambiguous gestural accentuation of the female genital in apotropaic figures (Sütterlin, 2016) was examined. Eveline Seghers' (2016) talk on ultimate and proximate factors in evolutionary thinking on art completes the selection of ISHE research topics displayed on its 2015 Summer Institute which can be retraced in this bulletin.

Besides a great conference program, our hosts also organized an unforgettable social program offering several culinary and cultural events. Among the cultural highlights, the instructive visit of the Acropolis museum and the Acropolis itself as well as the visit of the old parliament combined with a bus trip around the city center have to be emphasized. Finally, the exciting research and the impressive historical excursions were rounded up by the conference dinner held at a marvelous restaurant on the Lycabetus hill, which offered the most impressive view across Athens with all its ancient flair.

To put it in a nutshell, the 2015 ISHE summer institute was, as always, very stimulating and instructive for students who just started dealing with human behavior and evolution, and experienced researchers alike.

\section{ACKNOWLEDGEMENTS}

I want to especially thank the organizers Loukas Konstantinou and Zoe Tsioli, Craig Roberts who supported them and of course the program committee of the summer institute, the partaking members of the ISHE society who all made this meeting as exciting and 
enjoyable as every year. Thanks also to the authors who submitted their work into this special issue as well as to the reviewers who volunteered to carefully review the submissions.

\section{REFERENCES}

Sloan Kruger, J., Castor, T., Kruger, D.J. (2016). Caffeine and Calorie Consumption at a College Campus Coffee Café. Human Ethology Bulletin, 31(1), 74-83. DOI

Mikolić, A. (2016). Disgust and Facial Expression Recognition Across the Menstrual Cycle. Human Ethology Bulletin, 31(1), 60-73. DOI

Seghers, E. (2016) Proximate and Ultimate Factors in Evolutionary Thinking on Art. Human Ethology Bulletin, 31(1), 47-59. DOI

Sütterlin, Ch. (2016). Universals in Ritualized Genital Display of Apotropaic Female Figures. Human Ethology Bulletin, 31(1), 30-46. DOI

Weisfeld, G. \& Cronin Weisfeld, C. (2016). Is Play an Emotion? Some Ethological Observations. Human Ethology Bulletin, 31(1), 4-29. DOI 